This item was submitted to Loughborough's Research Repository by the author.

Items in Figshare are protected by copyright, with all rights reserved, unless otherwise indicated.

\title{
Manipulative imputation in distributed decision support settings: the implications of information asymmetry and aggregation complexity
}

\section{PLEASE CITE THE PUBLISHED VERSION}

http://dx.doi.org/10.1016/j.dss.2016.02.004

\section{PUBLISHER}

(C) Elsevier

VERSION

AM (Accepted Manuscript)

\section{PUBLISHER STATEMENT}

This work is made available according to the conditions of the Creative Commons Attribution-NonCommercialNoDerivatives 4.0 International (CC BY-NC-ND 4.0) licence. Full details of this licence are available at: https://creativecommons.org/licenses/by-nc-nd/4.0/

\section{LICENCE}

CC BY-NC-ND 4.0

\section{REPOSITORY RECORD}

Malekovic, Ninoslav, Juliana Sutanto, and Lazaros Goutas. 2019. "Manipulative Imputation in Distributed Decision Support Settings: The Implications of Information Asymmetry and Aggregation Complexity". figshare. https://hdl.handle.net/2134/21129. 


\title{
Manipulative Imputations in a Distributed Decision Support Setting:
}

\section{The Effects of Information Asymmetry and Information Aggregation Complexity}

\begin{abstract}
:
According to earlier research, distributed decision support structures are susceptible to deception. We complement the existing works by analyzing group members' attempts to manipulate group decisions supported by distributed communications. Experimentally, we manipulated two systemic features of a distributed support structure: the members' information asymmetry and decision rule complexity. Both of these features refer to structural properties of aggregated information exchange. We confirmed several hypothesized effects: An increase in the information asymmetry in the aggregation of information increases the incidence of the members' manipulative tendency. It also increases the effectiveness of the members' manipulative imputations. However, the complexity of a decision rule negatively moderates both of these effects. We point out the theoretical relevance and managerial implications of our findings. We conclude that managing team members' information asymmetry and complexity of issues under their practical consideration may result in valuable disclosures.
\end{abstract}

Key Words: deception; manipulative imputations; information aggregation; information asymmetry; decision rule complexity; lab experiment;

\section{Introduction}

Deceptive behaviors arguably constitute a thorny issue in modern societies (Griffith \& Peterson, 2006). Deception effectively refers to “a communicator's deliberate attempt to foster in others a belief or understanding which the communicator considers to be untrue'” (DePaulo \& DePaulo, 1989, p. 1553). In this respect, it can be seen as an intentional act that occurs when a focal actor create a desired effect, by controlling information in a message (Carlson et al., 2004; Miller \& Stiff, 1983). 
As the unique characteristics of the Internet (e.g. its low entry barriers, spatial/temporal separation, and anonymity) facilitate deceptive acts, such acts have largely been examined in the context of e-commerce (Pavlou \& Gefen, 2005; Xiao \& Benbasat, 2011). Nonetheless, recent studies have also started to examine deceptive acts within group decision support system (GDSS) settings. Examples of the latter include the study of deception in corporate prediction markets (O’Leary, 2015) and online preference markets, i.e., virtual markets established to collect participants' preference on virtual stocks representing items of interest (Chen et al., 2013). Earlier GDSS works have stressed the need to examine deceptive acts in GDSS settings, given that "the decisions that are guided by the GDSS may only be as good as the information that is exchanged” (Barkhi et al., 1998, p. 223).

Our study largely seeks to contribute to this line of research by providing a better understanding of the antecedents behind the genesis of deceptive acts in GDSS. As we also illustrate in the next section, a number of studies examined several factors that make individuals more susceptible to deception (Biros et al., 2002; George et al., 2014; Giboney et al., 2015; Vishwanath et al., 2011). They also examined the potential held by different technology features to aid individuals in detecting deception (Jarvenpaa \& Majchrzak, 2010; Twyman et al., 2014; Zhou et al., 2004). However, as the literature on online deception reveals, little is known in terms of understanding how group members can make use of technology features to deceive. In other words, more needs to be known about how technology features cause individuals to submit inauthentic information within group settings.

In light of the above, the focus of this paper is to understand how systemic GDSS features may inhibit or motivate an individual group member to impute inauthentic information. Our study examines such imputations during instances of information aggregation, as the pooling of information over many individuals making a group decision is referred to (Bettencourt, 2009; Csaszar \& Eggers, 2013). In particular, it examines the effects of two systemic GDSS features on 
the group member's tendency to deceive: 1) the presence of information asymmetries during the aggregation of information, and 2) the complexity characterizing this aggregation.

The difference between the information transacting parties possess, known as information asymmetry (Ba \& Pavlou, 2002), has been identified as a likely predictor of deceptive acts (Barkhi et al., 1998, 2004). In addition, regulative effects may suppress biased information exchange (Silver, 2014). Therefore, under conditions of information asymmetry, the complexity of a rule that determines how imputations are aggregated into a group outcome may differentially impact the exchange of inauthentic information.

Our study examines the effects of information asymmetry and decision rule complexity on the incidence of a group member submitting inauthentic information. In addition, we complement our analysis by examining the effectiveness of a group member's manipulative imputations on a supported group decision. The latter, while important, has been implicitly assumed. Hence, findings of this study initially inform GDSS researchers and practitioners on how one systemic feature, i.e. the asymmetry of information, may promote a deceptive act. Moreover, our study also illustrates the interplay between these two systemic features, influencing the group member's tendency to deceive. Specifically, it shows how the setting of a decision rule under conditions of information asymmetry can suppress an individual's submission of inauthentic information.

The rest of the paper is organized as follows: in the following section, we provide a brief overview of the findings on deception, and suggest how this applies to GDSS settings. In the subsequent section, we develop our hypotheses. In the fourth and fifth section, we explain our methodology and results. We then discuss our findings, research contributions, and managerial implications, and conclude the paper.

\section{Related Prior Works}




\subsection{Deception and Technology}

The previous works on the relationship between technology and deception followed two closely related research streams. One stream investigated characteristics that make individuals susceptible to deception. Urgency cues, habitual media use, and high email load play an important role in this susceptibility (Vishwanath et al., 2011). The credibility of a sender is also an important factor (George et al., 2014).

The other stream investigated characteristics that assist deception detection, by strengthening users’ vigilance (Jarvenpaa \& Majchrzak, 2010). Warnings about data quality combined with just-in-time training enhance deception detection (Biros et al., 2002). However, this comes at the cost of a user's evaluation time, and can increase the number of false alarms (Biros et al., 2002). Proposals have also been made for automated deception detection (Zhou et al., 2004). Recently proposed credibility assessment systems are capable of detecting individuals' purposely hidden information (Twyman et al., 2014). These systems synthesize the understanding of orienting and defensive responses, structured interviewing, and non-invasive psychophysiological and behavioral measurements (Twyman et al., 2014). Whereas many promising methods can assist deception detection, selecting valuable input variables remains unavoidable in enhancing their performance.

In spite of these important findings, little is known about how individuals appropriate technology features to deceive. Our study aims to address this important research gap. Specifically, we investigate how technology features cause individual group members to submit inauthentic information.

\subsection{Deception in GDSS settings}

Studies of deceptive acts in GDSS settings compared collocated groups and groups supported by distributed communications. Group members supported by distributed 
communications revealed their information less truthfully than collocated group members (Barkhi et al., 1998). This difference persisted even if the groups did not have a leader (Barkhi et al., 2004). Further, a recent study investigated the incidence of deception and the success of deceivers in influencing group decisions (Marett \& George, 2013). Across the board, the group members were abysmally poor at detecting lies submitted during group sessions (Marett \& George, 2013). Deceivers lied more if their group members were supported by distributed communications. However, they were significantly more successful in influencing group decisions if their group members were collocated (Marett \& George, 2013). A recent numerical analysis showed that regulative effects in distributed GDSS settings suppressed the bias of group members' information exchange (Silver, 2014).

Our study focuses on distributed GDSS settings that encourage the submission of inauthentic information. However, rather than comparing the physical features of GDSS settings (distributed communications vs. collocated groups) like these previous studies, our study examines effects of the systemic features common to the distributed communications. One such feature is the presence of information asymmetries during the aggregation of information (Barkhi et al., 1998). The other is the decision rule complexity that characterizes this aggregation (Silver, 2014).

In bilateral settings, a general requirement for a deceptive act to be effective is that deceiving signals generated by a deceiver reach the other party, and affect a decision outcome (Li \& Cruz, 2009). Only if the deceiver believes that manipulated information will affect the other party, will he/she opt to manipulate this information in his/her favor. Moreover, in GDSS settings, it is typically understood that the information necessary for a supported group decision to be made is distributed among group members. Thus, a supported group decision will be generally susceptible to every group member’s imputed information. 
In light of this condition, the GDSS settings beg two main questions: First, how to prevent a group member from imputing inauthentic information? Second, how to suppress the effectiveness of this imputation on a supported group decision? Our study addresses both of these questions.

\section{Theory and Hypotheses}

By-and-large, decision-making consists of information managing behaviors, i.e. the search for and processing of information, and evaluation and implementation of options (Csaszar \& Eggers, 2013; Gavetti et al., 2007; Simon, 1972, 1997). Intuitively, more information reduces uncertainty, and can lead to a better payoff. The value of this information is usually defined through the induced payoff difference (Feltham, 1968; Howard, 1966). Many deceptive acts draw on the 'informational leverage' held over decision-making parties (Clots-Figueras, et al. 2015). Such an imbalance is commonly referred to as information asymmetry.

Information asymmetry pervades distributed GDSS structures (Barkhi et al. 1998). This fact has led to hypothesizing that information asymmetry can be a key predictor of deceptive acts in a distributed GDSS structure (Barkhi et al. 2004). Siding with this argument, our study treats information asymmetry as a dynamic notion that can increase or decrease during an exchange of information, and in our case during its aggregation. A thorough understanding of these effects on deception requires an examination of changes in information that aggregates into a group outcome.

Our overarching hypothesis is that increased information asymmetry among group members will lead to a higher number of deceptive acts. If the pooled information on other members’ preferences is disclosed to an individual member, this disclosure reduces his/her uncertainty (Li \& Cruz, 2009). In addition, the disclosure of their conflicting incentives reveals to the individual member an opportunity to exploit his/her 'informational advantage.' The member responds to this opportunity, by manipulating information, thereby changing a group outcome, 
and improving his/her payoff (Volz et al., 2015). In other words, the increase in this asymmetry may increase the incidence of the member's attempted manipulation. Accordingly, we hypothesize:

H1a: An increase in information asymmetry during the aggregation of information increases a group member's manipulative tendency.

As already stated, an increase in information asymmetry occurs by providing the member with the information on the remaining members' conflicting incentives. Besides disclosing to the member the opportunity to manipulate group outcomes, this also informs the member of the likely consequences of his/her imputations. Specifically, such a disclosure informs the member of an imputation that may lead to group outcomes more favorable to him/her. Hence, an increase in information asymmetry should also cause the member's manipulative imputation to be more effective. Therefore, we hypothesize:

H1b: An increase in information asymmetry during the aggregation of information increases the effectiveness of a group member's manipulative imputation.

Either implicitly or explicitly, group decisions require a decision rule. Any such rule structures the aggregation of imputed information into a group outcome (Bettencourt, 2009). The simplest decision rule may require each group member to impute only a single preference (i.e. “Among options a, b, and c, I prefer option b.”). A more complex rule may require each group member to impute exhaustively ordered preferences (i.e. “Among options a, b, and c, I prefer options b, a, and c, in that order.”). An even more complex rule may require each group member to characterize his/her intensity of preferences across an imputed ordering (i.e. "Among options a, b, and c, I prefer option b three times more than option a, and option a two times more than option c.”). Obviously, the rules differ in the richness of information each member is required to impute. In addition, they also differ in the complexity of the aggregation of imputed information 
(Bettencourt, 2009; Endriss et al., 2012). We argue that this complexity may affect the relationship between the information asymmetry and deception.

Simple rules are known to positively influence group outcomes (Limayem et al., 2006). After all, the complexity of a decision rule is inversely related to the efficiency of information processing (Conitzer \& Sandholm, 2005; Xia \& Conitzer, 2010). As implied by the principle of bounded rationality, this complexity taxes an individual's information processing ability (Adler et al., 2011; Gigerenzer \& Goldstein, 1996; Simon, 1972). Hence, the more complex the rule, the lower is the efficiency of the individual group member's information processing. This consideration also applies to the efficiency of the member’s manipulative responses to any disclosed opportunity. As previously explained, the increase in information asymmetry about the other members' conflicting incentives discloses to the member the opportunity to manipulate group outcomes. This incentivizes the group member to manipulate information, thereby changing a group outcome, and improving his/her payoff. Nonetheless, if this complexity makes the member's information processing less efficient, he/she may also be less likely to respond to this opportunity. Hence, we hypothesize:

\section{H2a: The decision rule complexity negatively moderates the effect of information} asymmetry on a group member's manipulative tendency.

The inverse relationship between the complexity of a decision rule and efficiency of information processing also applies to the effectiveness of the group member's manipulative imputation. The disclosure of the remaining members' conflicting incentives informs the member's evaluation of his/her imputations. The disclosure of the opportunity to favorably manipulate group outcomes makes the member more likely to do so. However, the decision rule complexity taxes the efficiency of the member's information processing. This processing includes the member's selection of a manipulative imputation that favorably manipulates a group outcome. 
Thus, the more complex the rule, the lower is the effectiveness of the member's manipulative imputation. Accordingly, we hypothesize:

\section{H2b: The decision rule complexity negatively moderates the effect of information} asymmetry on the effectiveness of a group member's manipulative imputation.

Figure 1 illustrates our research model. We provide the specification of all the variables in the following section.

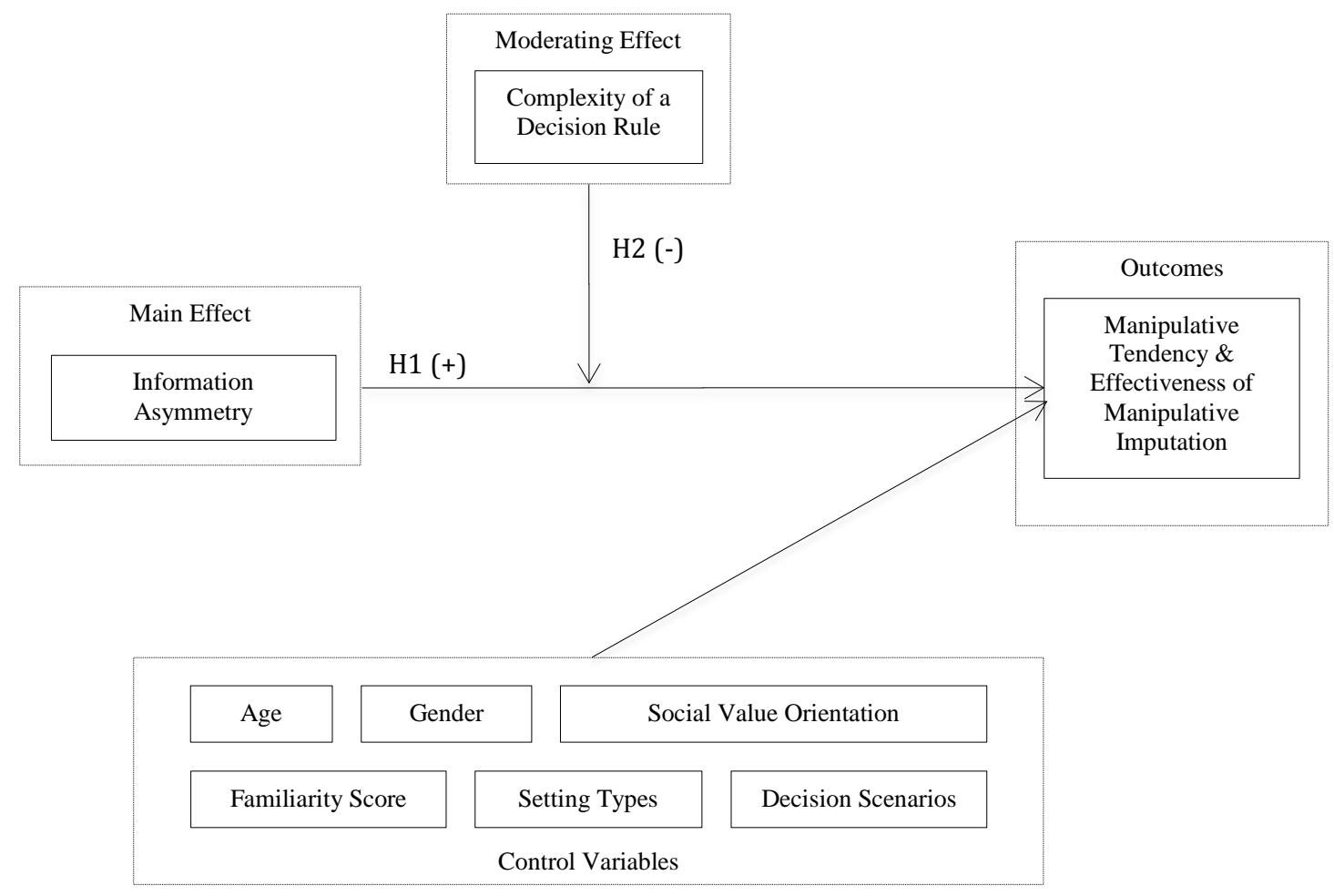

Figure 1. The Research Model With Main, Moderating, Control, and Dependent Variables

\section{Research Methodology}

\subsection{Participants and Experiment Design}

Our hypotheses were tested in a lab experiment. Our 120 participants were graduate students from a university in Central Europe. Their mean age was 24.41 (standard deviation = 4.49). Fifty-nine participants were female (49\%) and sixty-one were male (51\%). All the participants took part in nine decision scenarios. Each scenario assumed the existence of six other 
imaginary group members. Our treatment was the increased information asymmetry in the aggregation of information (low vs. high asymmetry). Our moderator was the decision rule complexity (low vs. moderate vs. high rule complexity). Since people differ in their tendency of becoming informed (Goldberg, 1993; Northouse, 2007), information asymmetry was varied between-participants. On the other hand, the same people may experience different decision situations. Thus, the decision rule complexity was varied within-participants. Finally, our dependent variables were the manipulative tendency and effectiveness of manipulative imputation.

\subsection{Pretesting the Decision Scenarios}

Initially, we devised a number of decision scenarios. Our rationale was for each scenario to consist of a specific decision rule and a specific preference arrangement. The previous analyses in the social choice (voting) informed our choice of these elements (e.g., Sobel, 2001; Taylor, 2002, 2005): only if participants imputed inauthentic information could they favorably change a group outcome. For the three rules, twelve preference arrangements were selected. This resulted in 36 scenarios. Prior to the experiment, we pretested the scenarios three times. Following the first pretest round, two of the 23 participants reported their overwhelming, exam-like experiences. Beyond the 12th scenario, they reportedly submitted random imputations. Therefore, 24 scenarios were eliminated.

In order to make the participants' experiences less exam-like, we enriched the remaining 12 scenarios with additional, descriptive elements. Prior studies on management informed our selection of the descriptive elements (e.g., Defourny \& Nyssens, 2010; MacKrell \& McDonald, 2014; Zhu et al., 2014). The descriptive elements correspond to the basic setting types (business vs. social) as well as more particular scenario descriptions. We embedded the previously selected rules and preference arrangements into these descriptive elements. Subsequently, additional 15 participants were invited to the second pretest round. This round confirmed that the embedding 
was done effectively. However, some of the descriptions strongly interfered with the participants' attitudes (for instance, an attitude toward the death penalty). After the subsequent modifications, nine scenarios remained. A vacation, a sports club, a donation, team building, and an evening outing were retained as social settings. In addition, a small business, a candy distribution, a corporate board, and an investment were retained as business settings. Eventually, we invited another 10 participants for the third pretest round. Their reports suggested the linguistically formulated variables were effective. In turn, their self-reports indicated they voted tactically whenever they could.

\subsection{Variables}

4.3.1 The Treatment: The participants in our control group only knew their assigned preferences and no one else’s. Being informed about the six imaginary members’ preferences, the participants in the experiment group were exposed to the increased information asymmetry. Our treatment was coded accordingly: the control group (low asymmetry $=0$ ) or the experiment group (high asymmetry = 1) (Please refer to Appendix A for the difference in the scenarios between the two groups).

4.3.2 The Moderating Variable: Our moderator was specified as a set of variably

complex decision rules. Such rules prescribe how the members' imputations are aggregated into a group outcome. The rules ranged from the simple majority over rank vote to points method. The aggregation of imputations across the rules reflects an increase in the complexity of their tally (Brams \& Herschbach, 2001, Conitzer \& Sandholm, 2005; Xia \& Conitzer, 2010). Notably, the simplest rule is the simple majority (Messner \& Polborn, 2004). This rule has each participant impute a preference for a single option. An outcome is an option that receives more than half of all the members' votes. A more complex rule is the rank vote. This rule has each participant impute a preference ordering (Islam et al., 2011; Saari, 2001). An outcome is an option that receives most group members' first rank. Finally, an even more complex rule is the point method 
(Guinier, 1994; Siegler \& Talel, 2005). This rule has each participant distribute an equal number of points across all options. Such a distribution accounts for the intensity of their preferences. An outcome is an option with the greatest sum of group members' points. Accordingly, our moderator was coded as low complexity (simple majority: rule $=0$ ), moderate complexity (rank vote: rule $=1$ ), or high complexity (the points method: rule $=2$ ). (Please refer to Table 1 for the scenarios with their respective rules).

4.3.3 The Dependent Variables: Earlier studies specified a deceptive act as a claim that diverges from a standard discussion script (George \& Marrett, 2004). An act of effective deception was specified as a discussant convincing the group to accept an option that the discussant did not sincerely prefer (Marrett \& George, 2013). We specified the participant’s manipulative imputation as his/her support for an option that is not preferred in accordance with the assigned preferences (Sobel, 2001; Taylor, 2002, 2005). Correspondingly, the first dependent variable was coded as an authentic (the most preferred imputation; inauthentic $=0$ ) or inauthentic imputation (not the most preferred imputation; inauthentic =1). The participants were prompted to impute their preferences. By calculating consequent group outcomes, we specified the effectiveness of an inauthentic imputation. Hence, the second dependent variable was coded as an ineffective (an inauthentic imputation that does not preclude a less preferred outcome; effective = 0) or effective manipulative imputation (an inauthentic imputation that precludes a less preferred outcome; effective =1). Finally, all possible outcomes were combined into a third dependent variable. This variable was coded as an authentic imputation (manipulate $=0$ ), ineffective manipulative imputation (manipulate $=1$ ), or effective manipulative imputation (manipulate $=2$ ).

4.3.4 The Control Variables: Among our control variables, our first variable controlled for the participants' age. Due to a possible effect of gender on inauthentic disclosures (Dreber \& Johannesson, 2007; Erat \& Gneezy, 2012), our second control variable accounted for the participants' gender (male: gender $=0$, female: gender $=1$ ). Furthermore, the concern for others 
may affect inauthentic imputations. Hence, our third control variable accounted for the participants' social value orientation (Steinel \& De Dreu, 2004; Steinel et al., 2010). To this end, we used the social value orientation index (Murphy et al., 2011): the greater the social value orientation index, the more social is the participant. An overview of the items used to compute this index can be found in Appendix B.

Our fourth control variable accounted for the basic setting type (Defourny \& Nyssens, 2010; MacKrell \& McDonald, 2014; Zhu et al., 2014). Across the nine decision scenarios (see Table 1 ), the basic setting type was coded as a business (setting $=0$ ) or social setting (setting $=1$ ). Moreover, our fifth control variable accounted for the remaining variability in the nine scenarios. These nine scenarios were coded as dummy variables: a vacation club (scenario $=1$ ), a sports club (scenario $=2$ ), a corporate board (scenario $=3$ ), a small business (scenario $=4$ ), donations ( cenario $=5$ ), candy distributor (scenario $=6$ ), investment (scenario $=7$ ), team building (scenario $=8$ ), or evening outing (scenario $=9$ ). To avoid a possible sequential effect, the participants' sequential exposure to these scenarios was randomized. Our final control variable accounted for the participants' familiarity with the scenarios. After each scenario, the participants responded to: “Did your preference in real life affect your choice in this scenario?” Their responses were coded on the Likert scale from “certainly not” (familiarity = 1) to "certainly yes” (familiarity = 7).

\begin{tabular}{|c|c|c|c|c|}
\hline & \multicolumn{3}{|c|}{ Complexity of a decision rule } \\
\hline & & Simple Majority & Rank Vote & Point Method \\
\hline \multirow[t]{2}{*}{$\begin{array}{l}\text { Information } \\
\text { asymmetry: }\end{array}$} & Low & $\begin{array}{c}\text { 1.1 Vacation } \\
\text { 1.2 Sports Club } \\
\text { 1.3 Corporate Board }\end{array}$ & $\begin{array}{l}\text { 1.4 Small Business } \\
\text { 1.5 Donation } \\
\text { 1.6 Candy Distribution }\end{array}$ & $\begin{array}{l}1.7 \text { Investment } \\
\text { 1.8 Team Building } \\
\text { 1.9 Evening Outing }\end{array}$ \\
\hline & High & $\begin{array}{c}\text { 2.1 Vacation } \\
\text { 2.2 Sports Club } \\
\text { 2.3 Corporate Board } \\
\end{array}$ & $\begin{array}{c}\text { 2.4 Small Business } \\
\text { 2.5 Donation } \\
\text { 2.6 Candy Distribution }\end{array}$ & $\begin{array}{c}\text { 2.7 Investment } \\
\text { 2.8 Team Building } \\
\text { 2.9 Evening Outing }\end{array}$ \\
\hline
\end{tabular}

Table 1 Experiment scenarios relative to the information asymmetry and complexity of a decision rule 


\subsection{Manipulation Checks}

If measured simultaneously, the manipulation checks could interfere with the measurement of our dependent variable. Therefore, for the manipulation checks we chose another independent sample of 27 pretest participants. Testing the effectiveness of the increased information asymmetry, we presented the participants with the nine decision scenarios. They were asked to pinpoint an opportunity of precluding their less desirable group outcomes. Then we tested the difference between the expected and observed distributions of their correctly detected opportunities across all the scenarios. $\chi^{2}$ pointed to no difference between them $(\chi 2=11.259$, d. $\mathrm{f}$. $=8, \mathrm{p}=0.1874, \mathrm{n}=27$ ). The pretest participants correctly detected all such opportunities. Thus, our treatment was effective.

Further, testing the effectiveness of the decision rule complexity, we asked these pretest participants to rank the rules for their complexity. Their ranks were to range from the least over moderately to most complex rule. Specifically, they were expected to rank the simple majority as the least complex rule, the rank vote as the moderately complex one, and the point method as the most complex one. Then we tested the difference between the expected and observed

distributions of their ranks. $\chi^{2}$ pointed to no difference between these distributions $\left(\chi^{2}=2.741\right.$, $\mathrm{d}$. $\mathrm{f} .=2, \mathrm{p}=0.254, \mathrm{n}=27$ ). Therefore, our moderating variable was also effectively manipulated.

\subsection{Experiment Procedure}

Our participants (120 graduate students from a university in Central Europe) were assigned to their respective computer booths in a laboratory. They were randomly assigned to the control or experiment group. They were presented with on-screen instructions, instructing them to read each scenario and impute their information. Their exposure to the scenario sequences was also randomized. They were instructed to impute what for them constitutes a favorable outcome. All the responses were collected automatically. On average, the experimental group took 57 
minutes, and the control group took 43 minutes to complete the assignment. Finally, the participants’ anonymity was guaranteed, and their participation was compensated.

\section{Results}

\subsection{Descriptive Statistics}

Table 2 shows our participants’ characteristics. On average, the participants' social value orientation falls between individualistic and perfectly equitable (Murphy et al. 2011).

\begin{tabular}{|r|c|c|c|c|}
\hline Group & Age & Gender (m/f) & Social Value Orientations & Total (N) \\
\hline $\begin{array}{c}\text { Control group (Low } \\
\text { information asymmetry) }\end{array}$ & $24.433(3.334)$ & $28 / 32$ & $26.893(14.824)$ & 60 \\
\hline $\begin{array}{c}\text { Experiment group (High } \\
\text { information asymmetry) }\end{array}$ & $24.383(5.398)$ & $33 / 27$ & $24.913(17.063)$ & 60 \\
\hline
\end{tabular}

Table 2. Participants’ characteristics (standard deviations are in the parentheses)

Table 3 displays the likelihood of different imputations relative to the information asymmetry. This gives the initial idea of the participants' manipulative tendencies and their effectiveness.

\begin{tabular}{|r|c|c|c|}
\hline Group & Authentic imputation & $\begin{array}{c}\text { Ineffective } \\
\text { manipulation }\end{array}$ & $\begin{array}{c}\text { Effective } \\
\text { manipulation }\end{array}$ \\
\hline $\begin{array}{c}\text { Control group (Low } \\
\text { information asymmetry) }\end{array}$ & $0.741(0.019)$ & $0.141(0.015)$ & $0.119(0.015)$ \\
\hline $\begin{array}{c}\text { Experiment group (High } \\
\text { information asymmetry) }\end{array}$ & $0.196(0.017)$ & $0.089(0.012)$ & $0.715(0.019)$ \\
\hline
\end{tabular}

Table 3. Descriptive statistics for authentic and manipulative imputations (standard deviations are in the parentheses)

\section{2 Main Analyses}


Given our categorical measure, we initially employed a logistic regression. As stated previously, the first dependent variable is specified as an authentic (inauthentic $=0$ ) or inauthentic imputation (inauthentic $=1$ ). The second dependent variable is specified as an ineffective (effective $=0$ ) or effective manipulative imputation (effective $=1$ ). Table 4 shows the results of our tests for the first and second dependent variables:

\begin{tabular}{|c|c|c|c|c|}
\hline & \multicolumn{2}{|c|}{$\begin{array}{l}\text { Authentic vs. Inauthentic } \\
\text { Imputation }\end{array}$} & \multicolumn{2}{|c|}{$\begin{array}{l}\text { Ineffective vs. Effective } \\
\text { Manipulative Imputation }\end{array}$} \\
\hline \multicolumn{5}{|l|}{ CONTROL VARIABLES: } \\
\hline Age & $\begin{array}{l}-0.015 \\
(0.016)\end{array}$ & $\begin{array}{l}-0.016 \\
(0.016)\end{array}$ & $\begin{array}{l}-0.014 \\
(0.030)\end{array}$ & $\begin{array}{l}-0.013 \\
(0.030)\end{array}$ \\
\hline Gender & $\begin{array}{c}0.001 \\
(0.150)\end{array}$ & $\begin{array}{c}0.001 \\
(0.152)\end{array}$ & $\begin{array}{l}0.526^{*} \\
(0.249)\end{array}$ & $\begin{array}{l}0.527^{*} \\
(0.250)\end{array}$ \\
\hline Social Value Orientation (SVO) & $\begin{array}{c}0.014 * * \\
(0.005)\end{array}$ & $\begin{array}{c}0.014 * * \\
(0.005)\end{array}$ & $\begin{array}{l}-0.017 * \\
(0.009)\end{array}$ & $\begin{array}{l}-0.017 * \\
(0.009)\end{array}$ \\
\hline Familiarity Score & $\begin{array}{c}0.116^{* * *} \\
(0.034)\end{array}$ & $\begin{array}{l}0.121^{* * *} \\
(0.035)\end{array}$ & $\begin{array}{c}-0.147 * * \\
(0.057)\end{array}$ & $\begin{array}{c}-0.148^{* *} \\
(0.057)\end{array}$ \\
\hline \multicolumn{5}{|l|}{ Basic Setting - Business (baseline) } \\
\hline Social & $\begin{array}{c}0.060 \\
(0.203)\end{array}$ & $\begin{array}{c}0.233 \\
(0.181)\end{array}$ & $\begin{array}{l}-0.364 \\
(0.399)\end{array}$ & $\begin{array}{c}0.078 \\
(0.318)\end{array}$ \\
\hline \multicolumn{5}{|l|}{ Scenarios - Corporate Board (baseline) } \\
\hline Vacation & $\begin{array}{l}-0.105 \\
(0.204)\end{array}$ & $\begin{array}{l}-0.276 \\
(0.249)\end{array}$ & $\begin{array}{c}0.525 \\
(0.384)\end{array}$ & $\begin{array}{c}0.067 \\
(0.407)\end{array}$ \\
\hline Sports & $\begin{array}{l}-0.075 \\
(0.204)\end{array}$ & $\begin{array}{l}-0.247 \\
(0.249)\end{array}$ & $\begin{array}{l}1.422^{* *} \\
(0.538)\end{array}$ & $\begin{array}{c}0.964 \\
(0.537)\end{array}$ \\
\hline Small Business & $\begin{array}{l}-0.670^{*} \\
(0.317)\end{array}$ & $\begin{array}{l}-0.234 \\
(0.217)\end{array}$ & $\begin{array}{l}-1.035 \\
(0.582)\end{array}$ & $\begin{array}{l}-0.533 \\
(0.375)\end{array}$ \\
\hline Donation & $\begin{array}{l}0.266 \\
(0.206)\end{array}$ & $\begin{array}{c}0.482^{* *} \\
(0.176)\end{array}$ & $\begin{array}{c}0.285 \\
(0.335)\end{array}$ & $\begin{array}{c}0.297 \\
(0.290)\end{array}$ \\
\hline Candy Distribution & $\begin{array}{l}-0.584 \\
(0.317)\end{array}$ & $\begin{array}{l}-0.153 \\
(0.215)\end{array}$ & $\begin{array}{l}-0.744 \\
(0.595)\end{array}$ & $\begin{array}{l}-0.245 \\
(0.382)\end{array}$ \\
\hline Investment & $\begin{array}{l}-0.235 \\
(0.316)\end{array}$ & $\begin{array}{c}0.137 \\
(0.221)\end{array}$ & $\begin{array}{l}-1.254^{*} \\
(0.548)\end{array}$ & $\begin{array}{l}-0.108 \\
(0.370)\end{array}$ \\
\hline Team Building & $\begin{array}{c}0.353 \\
(0.206)\end{array}$ & $\begin{array}{c}0.447 * * \\
(0.171)\end{array}$ & $\begin{array}{c}-1.803 * * * \\
(0.294)\end{array}$ & $\begin{array}{c}-1.168 * * \\
(0.282)\end{array}$ \\
\hline Evening Outing & $\begin{array}{l}-0.378 \\
(0.204)\end{array}$ & $\begin{array}{l}-0.172 \\
(0.171)\end{array}$ & $\begin{array}{l}-0.793^{*} \\
(0.329)\end{array}$ & $\begin{array}{l}-0.082 \\
(0.284)\end{array}$ \\
\hline
\end{tabular}


Information asymmetry - Low Asymmetry (baseline)

$$
\begin{array}{ccc}
\text { High asymmetry } & 2.636^{* * *} & 2.197^{* * *} \\
& (0.158) & (0.261)
\end{array}
$$

TREATMENT * MODERATOR:

Information asymmetry * Complexity of a decision rule - Low Asymmetry * Simple Majority (baseline)

Low Asymmetry * Rank Vote

0.095

$-0.481$

$(0.223)$

$(0.412)$

Low Asymmetry * Point Method

$0.411^{*}$

$-1.358 * * *$

$(0.187)$

(0.359)

High Asymmetry * Simple Majority

3.799***

$2.023 * * *$

(0.326)

(0.543)

High Asymmetry * Rank Vote

$-1.324 * *$

0.001

(0.416)

(0.697)

High Asymmetry * Point Method

$-1.896 * * *$

0.405

(0.404)

(0.676)

R-squared

0.405

0.426

0.395

0.397

Statistical significance at *: 95\%, **: 99\%, ***: 99.9\%

Table 4. Regression results (standard errors are in the parentheses)

H1a posits that the increase of information asymmetry increases the group member's manipulative tendency. The estimated coefficient in the first column of Table 4 (beta high asymmetry $=$ 2.636, standard error $=0.158$ ) supports H1a. H1b posits that the increase in information asymmetry increases the effectiveness of the group member's manipulative imputation. The estimated coefficient in the third column of Table 4 (beta high asymmetry $=2.197$, standard error $=$ 0.261 ) supports H1b. The models fit the data reasonably well (McFadden's $R$-squared $=0.405$ and 0.395 , respectively).

H2a posits that the complexity of a decision rule negatively moderates the effect of information asymmetry on the group member's manipulative tendency. The corresponding result is in the second column of Table 4. In the situation where an individual member has information on the other members' preferences (increased information asymmetry), as the decision rule becomes increasingly more complex, the tendency to impute inauthentic information becomes ever more reduced (beta high asymmetry $*$ simple majority $=3.799$; standard error $=0.326$; beta high asymmetry $*$ 
rank vote $=-1.324 ;$ standard error $=0.416 ;$ beta high asymmetry $*$ point method $=-1.896$, standard error $=$ 0.404). However, in the situation of low information asymmetry, the most complex decision rule increases the tendency to impute inauthentic information (beta low asymmetry * point method $=0.411$, standard error $=0.187)$. Hence, H2a is partially supported. Further, H2b posits that the complexity of a decision rule negatively moderates the effect of information asymmetry on the effectiveness of the group member's manipulative imputation. The corresponding result is in the fourth column of Table 4. If the information asymmetry is high, the least complex decision rule increases the effectiveness of the group member's manipulative imputation (beta high asymmetry * simple majority $=2.023$, standard error $=0.543$ ). However, if the information asymmetry is low, then the most complex rule reduces the effectiveness of the group member's manipulative imputation (beta low asymmetry * point method $=-1.358$, standard error $=0.359)$. Hence, H2b is partially supported.

Among the modifiers, there are several interesting findings: while the participant's social value orientation surprisingly increases the tendency to impute inauthentic information (beta social value orientation $=0.014$, standard error $=0.005)$, it reduces the effectiveness of manipulative imputation ( beta social value orientation $=-0.017$, standard error $=0.009)$. Moreover, while familiarity with the scenarios increases the tendency to impute inauthentic information (beta familiarity score = 0.121, standard error $=0.035$ ), it reduces the effectiveness of manipulative imputation (beta familiarity score $=-0.148$, standard error $=0.057)$. The reason for the first peculiar finding could be because the participants did not interact with real group members, while the reason for the second finding could be the participant's over-confidence.

Finally, we ran multinomial regressions on the third dependent variable. This variable was specified as an authentic (manipulate $=0$ ), ineffective manipulative (manipulate $=1$ ), or effective manipulative imputation (manipulate $=2$ ). Table 5 shows the results of the multinomial regression analyses.

Authentic vs. Authentic vs. Authentic vs. Authentic vs. 


\begin{tabular}{|c|c|c|c|c|}
\hline & $\begin{array}{l}\text { Ineffective } \\
\text { Manipulative } \\
\text { Imputation }\end{array}$ & $\begin{array}{l}\text { Effective } \\
\text { Manipulative } \\
\text { Imputation }\end{array}$ & $\begin{array}{l}\text { Ineffective } \\
\text { Manipulative } \\
\text { Imputation }\end{array}$ & $\begin{array}{l}\text { Effective } \\
\text { Manipulative } \\
\text { Imputation }\end{array}$ \\
\hline \multicolumn{5}{|l|}{ CONTROL VARIABLES: } \\
\hline Age & $\begin{array}{l}-0.007 \\
(0.026)\end{array}$ & $\begin{array}{l}-0.013 \\
(0.017)\end{array}$ & $\begin{array}{l}-0.007 \\
(0.026)\end{array}$ & $\begin{array}{l}-0.013 \\
(0.018)\end{array}$ \\
\hline Gender & $\begin{array}{l}-0.353 \\
(0.216)\end{array}$ & $\begin{array}{c}0.189 \\
(0.169)\end{array}$ & $\begin{array}{l}-0.353 \\
(0.217)\end{array}$ & $\begin{array}{c}0.190 \\
(0.170)\end{array}$ \\
\hline Social Value Orientation (SVO) & $\begin{array}{c}0.027 * * * \\
(0.008)\end{array}$ & $\begin{array}{c}0.010 \\
(0.005)\end{array}$ & $\begin{array}{c}0.027 * * * \\
(0.008)\end{array}$ & $\begin{array}{l}0.010^{*} \\
(0.006)\end{array}$ \\
\hline Familiarity Score & $\begin{array}{c}0.263 * * * \\
(0.048)\end{array}$ & $\begin{array}{c}0.040 \\
(0.039)\end{array}$ & $\begin{array}{c}0.265^{* * *} \\
(0.048)\end{array}$ & $\begin{array}{c}0.044 \\
(0.040)\end{array}$ \\
\hline \multicolumn{5}{|l|}{ Basic Setting - Business (baseline) } \\
\hline Social & $\begin{array}{c}0.360 \\
(0.371)\end{array}$ & $\begin{array}{c}-0.168 \\
(0.230)\end{array}$ & $\begin{array}{c}0.094 \\
(0.295)\end{array}$ & $\begin{array}{c}0.182 \\
(0.196)\end{array}$ \\
\hline \multicolumn{5}{|l|}{ Scenarios - Corporate Board (baseline) } \\
\hline Vacation & $\begin{array}{l}-0.308 \\
(0.355)\end{array}$ & $\begin{array}{c}0.185 \\
(0.230)\end{array}$ & $\begin{array}{l}-0.046 \\
(0.388)\end{array}$ & $\begin{array}{l}-0.151 \\
(0.267)\end{array}$ \\
\hline Sports & $\begin{array}{c}-1.263^{*} \\
(0.515)\end{array}$ & $\begin{array}{c}0.318 \\
(0.229)\end{array}$ & $\begin{array}{l}-0.977 \\
(0.520)\end{array}$ & $\begin{array}{l}-0.011 \\
(0.265)\end{array}$ \\
\hline Small Business & $\begin{array}{c}0.302 \\
(0.524)\end{array}$ & $\begin{array}{c}-1.045^{* *} \\
(0.356)\end{array}$ & $\begin{array}{c}0.092 \\
(0.325)\end{array}$ & $\begin{array}{c}-0.475^{*} \\
(0.247)\end{array}$ \\
\hline Donation & $\begin{array}{c}0.304 \\
(0.311)\end{array}$ & $\begin{array}{l}0.493 * \\
(0.233)\end{array}$ & $\begin{array}{c}0.358 \\
(0.271)\end{array}$ & $\begin{array}{c}0.627 * * \\
(0.195)\end{array}$ \\
\hline Candy Distribution & $\begin{array}{c}0.159 \\
(0.539)\end{array}$ & $\begin{array}{c}-0.787 * \\
(0.355)\end{array}$ & $\begin{array}{c}-0.053 \\
(0.335)\end{array}$ & $\begin{array}{l}-0.231 \\
(0.241)\end{array}$ \\
\hline Investment & $\begin{array}{l}0.982 * \\
(0.493)\end{array}$ & $\begin{array}{l}-0.730 * \\
(0.359)\end{array}$ & $\begin{array}{c}0.285 \\
(0.320)\end{array}$ & $\begin{array}{c}0.063 \\
(0.255)\end{array}$ \\
\hline Team Building & $\begin{array}{c}1.274^{* * *} \\
(0.254)\end{array}$ & $\begin{array}{c}-0.391 \\
(0.241)\end{array}$ & $\begin{array}{c}0.833^{* * *} \\
(0.214)\end{array}$ & $\begin{array}{c}0.026 \\
(0.208)\end{array}$ \\
\hline Evening Outing & $\begin{array}{c}0.352 \\
(0.279)\end{array}$ & $\begin{array}{c}-0.772 * * * \\
(0.232)\end{array}$ & $\begin{array}{c}-0.075 \\
(0.232)\end{array}$ & $\begin{array}{l}-0.308 \\
(0.204)\end{array}$ \\
\hline \multicolumn{5}{|c|}{ TREATMENT: } \\
\hline High asymmetry & $\begin{array}{c}0.851^{* * *} \\
(0.232)\end{array}$ & $\begin{array}{c}3.306^{* * *} \\
(0.187)\end{array}$ & & \\
\hline \multirow{2}{*}{\multicolumn{5}{|c|}{$\begin{array}{l}\text { TREATMENT * MODERATOR: } \\
\text { Information asymmetry * Complexity of a decision rule: Low Asymmetry * Simple Majority (baseline) }\end{array}$}} \\
\hline & & & & \\
\hline Low Asymmetry * Rank Vote & & & $\begin{array}{c}0.398 \\
(0.339)\end{array}$ & $\begin{array}{l}-0.079 \\
(0.270)\end{array}$ \\
\hline Low Asymmetry * Point Method & & & $1.043 * * *$ & -0.219 \\
\hline
\end{tabular}


Statistical significance at *: 95\%, **: 99\%, ***: 99.9\%

Table 5. The effects on manipulative imputations (the authentic imputation is the baseline; standard errors are in the parentheses)

The results in Table 5 are generally consistent with the results in Table 4. The multinomial analyses entirely support H1a and H1b, and partially support H2a and H2b. While the former two hypotheses are quite straightforward, the latter two require a further explanation.

Essentially, H2 posits that rule complexity negatively moderates the effect of increased information asymmetry on the tendency to submit inauthentic information and the effectiveness of manipulative imputation. In the situation of high information asymmetry, if the decision rule is the least complex, the individual group member is more likely to impute inauthentic information $($ beta high asymmetry $*$ simple majority $=1.757$, standard error $=0.560)$, effectively manipulating a group outcome (beta high asymmetry * simple majority $=4.012$, standard error $=0.338)$. Given an increase in information asymmetry, an increase in the rule complexity decreases the likelihood of an inauthentic imputation (beta high asymmetry $*$ rank vote $=-0.855$, standard error $=0.688$; beta high asymmetry $*$ point method $=-1.281$, standard error $=0.640$ ). This also holds for the effectiveness of manipulative imputation (beta high asymmetry $*$ rank vote $=-0.953$, standard error $=0.457$; beta high asymmetry $*$ point method $=$ -1.159 , standard error $=0.465)$. However, in the situation of low information asymmetry with the most complex rule, the participant is more likely to impute inauthentic information (beta low asymmetry $*$ point method $=1.043$, standard error $=0.278)$. Nonetheless, he/she is unlikely to be effective at favorably manipulating a group outcome. In this situation, we see the evidence of a chance 
behavior. Since the decision rule is so complex, even without knowing the other group members' preferences, an individual is tempted to manipulate a group outcome, by taking a chance on this. The next section presents a more detailed discussion of the findings.

\section{Discussion}

Individuals may attempt deceiving acts within group settings. They are more likely to do this if their groups are supported by distributed communications (Barkhi et al., 1998, 2004; Marrett \& George, 2013). However, the effectiveness of their attempts on supported group decisions has not been clear (Marrett \& George, 2013). In line with these findings, we subjected the group members' manipulative attempts to the impact of the two systemic features of distributed support. Our study examined how information asymmetry and rule complexity influence the group member's manipulative tendency and its effectiveness on supported group decisions.

Providing information on the other members' conflicting incentives increases the group member’s manipulative tendency. Given the simple decision rule, doing so also increases the effectiveness of the member's manipulative imputation. As the decision rule is made more complex, the inability to cope with the additional complexity burdens the member's manipulative tendency. Interestingly, a feature of a decision rule may give the member an option to 'stake the odds,' by imputing inauthentic information. The member is likely to take this chance, even if he/she does not have any information about the other members’ preferences. Specifically, the most complex rule in our experiment, i.e. the point method, requires from each participant to distribute a pre-specified number of points across all possible options (e.g., “Among options a, b, and c, I prefer option b three times more than option a, and option a two times more than option c”). Such a distribution accounts for the intensity of the member's preferences. An outcome is an option with the greatest sum of all the group members’ points. Without knowing the preferences of the other members, our participants overemphasized the intensity of their authentic 
preferences. They did so in a bid to assure the group outcome that is more favorable to them. However, without knowing the other members’ preferences, simply 'staking the odds' turned out ineffective. Despite the ineffectiveness, this finding additionally points to the susceptibility of systemic GDSS features to manipulative imputations.

Our other findings concern control variables. While the social value orientation increases the participants' tendency to impute inauthentic information, it reduces the effectiveness of their manipulative imputations on supported group decisions. A lack of interaction with the other group members in the experiment setting could have caused this peculiar finding. Moreover, while the familiarity with the scenarios increases the participants' tendency to impute inauthentic information, it also reduces the effectiveness of their manipulative imputation. A possible reason for this is the participants' over-confidence. Notably, over-confidence may lead individuals to rush with their imputations (Harvey, 1997; Moore \& Healy, 2008). It may be interesting for future studies to further explore these effects.

\subsection{Research Contributions}

Our study makes a number of important research advances. First, we holistically examined the incidence and effectiveness of the group member's manipulative influences over supported group decisions. Earlier works mainly focused on the incidence, while ignoring the effectiveness. Our findings thus enrich the existing GDSS literature, and are an important stepping stone toward future studies that delve deeper into the effectiveness of manipulative imputations in distributed GDSS settings.

Second, most GDSS studies (e.g., Barkhi et al., 1998, 2004) compared the group members' exchange of inauthentic information between different physical features of GDSS settings (i.e., distributed versus collocated). Their common finding is that the exchange of inauthentic information is more prevalent in a distributed GDSS setting. Our study delved deeper into the distributed GDSS setting by examining the effect of two systemic features, i.e., 
information asymmetry and decision rule complexity, on an individual member's tendency to impute inauthentic information. By eliminating the group member's interactions with the other group members, we eliminated the potential social considerations that may emerge from such interactions (i.e., we presented the experiment participants with six other imaginary group members). By doing so, we isolated the effects of the systemic GDSS features on the group member's manipulation tendency and its effectiveness. Future studies can build on our findings, by introducing and manipulating the social aspects, e.g., conducting an experiment with the group members being the participants' friends versus strangers.

Third, our findings inform the framework of information aggregation. Recall that this framework explains distributed decisions "through principles of minimization of uncertainty or maximization of predictability under information pooling over many individuals” (Bettencourt, 2009, pp. 598). Our findings show that an increase in the information asymmetry decreases the uncertainty of an effectively manipulated information aggregation outcome. However, the complexity of an information aggregation rule may suppress the effectiveness of an individual's manipulation, by increasing the uncertainty of such an outcome. The framework can be augmented and extrapolated, by including more complex manipulative behaviors into the analysis. In view of the pervasive impact of coalitions on supported group decisions (e.g., Burnett et al., 2014; French, 2007; Kilgour et al., 2001; Li et al., 20014; Xu et al., 2010), future research can extend ours, by studying more complex manipulative behaviors. Some such behaviors are: 1) coalitions that coordinate manipulative imputations, 2) strategic proposals that manipulate information aggregation, or 3) agenda rigging influences (French, 2007).

Fourth, our results have some consequences for the design of organizations. Some researchers refer to prediction markets that organizations use to support corporate decisions as GDSS (O'Leary, 2015). Such markets are designed to aggregate information from different sources with market prices reflecting the magnitude of support for available options (Chen et al., 
2013; O'Leary, 2015). Whereas the success of these markets depends on participants' contributed information, the reliability of their contribution is an issue (Chen et al., 2013; Yang et al., 2015). On the one hand, there is the inconsistency between the participants' surveyed and true preferences, as revealed during and/or after participation. Notably, up to $27 \%$ participants misstate their true preferences (Chen et al., 2013). In other words, the influence of information aggregation on stated preferences points to the inaccuracy of their disclosure. On the other hand, information traders who trade on specific information in a prediction market are themselves subject to information asymmetries (O'Leary, 2015). By affecting the information aggregation efficiency, the transparency of contributed information impedes such trading behaviors, rather than enticing them (Yang et al., 2015). Therefore, our findings strengthen the insight that less transparent information opens the door for deceptive acts. However, more research is needed on institutionally structured arrangements that minimize deception, and encourage trust facilitating exchanges.

\subsection{Implications for Practitioners}

Opportunities to assure a more desirable or preclude a less desirable group outcome incentivize team members’ manipulative behaviors. If there are competing interests on a manager's team, he/she can suppress or decrease the effectiveness of the members' attempted manipulations. A straightforward approach is for the manager to deprive any team member of knowledge of the other team members' competing interests. An alternative approach relies on the complexity. This complexity should be understood as the complexity of the team members' manipulation calculus. This complexity can also suppress or decrease the effectiveness of the team members’ attempted manipulations: for example, the manager can make the interdependence of the team members' competing interests more ambiguous. This would result in the team member's more authentic information disclosures. Thus, if issues under consideration 
are more complex, this will naturally result in their more authentic disclosures, due to the complexity of manipulation calculus.

In short, our advice is for managers to be well informed on issues reflecting the interdependence of their team members' competing interests. We advise them to cultivate the sensibility not only to the team members' manipulative imputations, but also to their more general information-managing behaviors. Such knowledge may also improve the design of GDSS features that prevent manipulative imputations. In this respect, the more cogent understanding of the susceptibility of a distributed support structure to such imputations is our contribution to the analysis and design of GDSS.

\section{References}

1. Adler, B. M., Baets, W., and König, R. (2011) “Complexity perspective on collaborative decision making in organizations: The ecology of group performance,” Information and Management, 48(4-5), pp. 157-165

2. Ba, S., and Pavlou, P. A. (2002) "Evidence of the effect of trust building technology in electronic markets: Price premiums and buyer behavior,” MIS quarterly, 26(3), pp. 243268

3. Barkhi, R., Jacob, V.S., Pipino, L., and Pirkul, H. (1998) “A study of the effect of communication channel and authority on group decision processes and outcomes,” Decision Support Systems, 23(3), pp. 205-226

4. Barkhi, R., Jacob, V.S., and Pirkul, H. (2004) "The influence of communication mode and incentive structure on GDSS process and outcomes,” Decision Support Systems, 37(2), pp. 287-305

5. Bettencourt, L. M. A. (2009) “The Rules of Information Aggregation and Emergence of Collective Intelligent Behavior,” Topics in Cognitive Science, 1(4), 598-620 
6. Biros, D. P., George, J. F., and Zmud, R. W. (2002) “Inducing sensitivity to deception in order to improve decision making performance: A field study,” MIS quarterly, 26(2), pp. $119-144$

7. Brams, S. J., and Herschbach, D. R. (2001) "The Science of Elections," Science, 1449, 292

8. Burnett, C., Norman, T.J., Sycara, K., and Oren, N. (2014) "Supporting trust assessment and decision making in coalitions,” IEEE Intelligent Systems, 29(4), pp. 18-24

9. Carlson, J. R., George, J. F., Burgoon, J. K., Adkins, M., and White, C. H. (2004)

“Deception in computer-mediated communication,” Group decision and negotiation, 13(1), 5-28

10. Chen L., Marsden, J. R., and Zhang Z. (2013) “Reliability (or “lack thereof”) of on-line preference revelation: A controlled experimental analysis,” Decision Support Systems, 56, pp. 270-274

11. Clots-Figueras, I., Hernan-Gonzales, R., and Kujal, P. (2015) “Information asymmetry and deception,” Frontiers in Behavioural Neuroscience, 9, pp.109

12. Conitzer, V., and Sandholm, T. (2005) “Communication complexity of common voting rules,” In Proceedings of the 6th ACM Conference on Electronic Commerce (EC), Vancouver, British Columbia, Canada, 5(8), pp. 78-87, New York, NY: Association for Computing Machinery

13. Csaszar, F. A., and Eggers, J. P. (2013) “Organizational decision-making: An information aggregation view,” Management Science, 59(10), 2257-2277

14. Defourny, J., and Nyssens, M. (2010) “Conceptions of social enterprise and social entrepreneurship in Europe and the United States: Convergences and divergences,” Journal of Social Entrepreneurship, 1(1), pp. 32-53 
15. DePaulo, P. J., and DePaulo, B. M. (1989). Can deception by salespersons and customers be detected through non-verbal behavioral cues? Journal of Applied Social Psychology, 19, 1552-1577.

16. Dreber, A., and Johannesson, M. (2008) “Gender differences in deception,” Economics Letters, 99(1), 197-199

17. Endriss, U. Grandi, U. and Porello, D. (2012) “Complexity of Judgment Aggregation,” Journal of Artificial Intelligence Research, 45, 481-514Erat, S., \& Gneezy, U. (2012) “White Lies,” Management Science, 58(4), 723-733

18. Erat, S., and Gneezy, U. (2012) “White Lies,” Management Science, 58(4), 723-733

19. Feltham, G. A. (1968) “The value of information,” Accounting Review, 4, pp. 684-696

20. French, S. (2007) “Web-enabled strategic GDSS, e-democracy and Arrow's theorem: A Bayesian perspective,” Decision Support Systems, 43 (4), pp. 1476-1484

21. Gavetti G., Levinthal D. A., and Ocasio W. (2007) “Neo-Carnegie: The Carnegie School's past, present, and reconstructing for the future,” Organization Science, 18(3), $523-536$

22. George, J. F., and Marett, K. (2004) “Inhibiting Deception and Its Detection,” Proceedings of the 37th Hawaii International Conference on System Sciences

23. George, J. F., Tilley, P., and Giordano, G. (2014) "Sender credibility and deception detection,” Computers in Human Behavior, 35, 1-11

24. Giboney, J. S., Brown, S. A., Lowry, P. B., and Nunamaker, J. F. (2015) “User acceptance of knowledge-based system recommendations: Explanations, arguments, and fit,” Decision Support Systems, 72, pp. 1-10

25. Gigerenzer, G. and Goldstein, D. (1996) “Reasoning the Fast and Frugal Way: Models of Bounded Rationality,” Cognitive Science, 103(4), 650-666

26. Goldberg, L. R. (1993) “The structure of phenotypic personality traits,” American Psychologist, 48, pp. 26-34 
27. Griffith, R. L., and Peterson, M. H. (2006) “A closer examination of applicant faking behavior,” Greenwich, CT: Information Age

28. Guinier, L. (1994) “The Tyranny of the Majority: Fundamental Fairness in Representative Democracy,” New York: The Free Press

29. Harvey, N. (1997) ”Confidence in judgment,” Trends in Cognitive Sciences 1(2), pp. 7882

30. Howard, R. A. (1966) "Information value theory,” IEEE Transactions on Systems Science and Cybernetics, 2(1), pp. 22-26.

31. Islam, J., Mohajan, H. and Moolio, P. (2011) "Methods of voting system and manipulation of voting,” International Journal of Management and Transformation, 5(1), pp. 10-34

32. Jarvenpaa, S. L., and Majchrzak, A. (2010). Research commentary-Vigilant interaction in knowledge collaboration: Challenges of online user participation under ambivalence. Information Systems Research, 21(4), 773-784

33. Kilgour, D.M., Hipel, K.W., Peng, X., and Fang, L. (2001) “Coalition Analysis in Group Decision Support,” Group Decision and Negotiation, 10(2), pp. 159-175

34. Li, D., and Cruz Jr., J. B. (2009) “Information, decision-making and deception in games,” Decision Support Systems, 47(4), pp. 518-527

35. Li, K. W., Inohara, T., and Xu, H. (2014) “Coalition analysis with preference uncertainty in group decision support,” Applied Mathematics and Computation, 231, pp. 307-319

36. Limayem, M., Banerjee, P., and Ma, L. (2006) “Impact of GDSS: Opening the black box,” Decision Support Systems, 42(2), pp. 945-957

37. MacKrell, D., and McDonald, C. (2014) “Action design research: A case study of business intelligence in non-profit organizations,” Frontiers in Artificial Intelligence and Applications, 261, pp. 291-302 
38. Marett, K., and George, J. F. (2013) “Barriers to Deceiving Other Group Members in Virtual Settings,” Group Decision and Negotiation, 22, pp. 89-115

39. Messner, M., and Polborn, M. K. (2004) “Voting on Majority Rules,” Review of Economic Studies, 71(1), 115-132

40. Miller, G. R., and Stiff, J. B. (1983) “Deceptive communication,” Newbury Park, CA: Sage.

41. Moore, D. A., and Healy, P. J. (2008) “The trouble with overconfidence,” Psychological Review, 115(2), pp. 502-517

42. Murphy, R. O., Ackermann, K. A., and Handgraaf, M. J. J. (2011) “Measuring Social Value Orientation. Judgment and Decision Making,” 6(8), pp. 771-781

43. Northouse, P. G. (2007). "Leadership: theory and practice,” 4th ed. Thousand Oaks, CA: Sage Publications

44. O'Leary, D. E. (2015) “User participation in a corporate prediction market,” Decision Support Systems, 78, 28-38

45. Pavlou, P., and Gefen, D. (2005) "Psychological contract violation in online marketplaces: Antecedents, consequences, and moderating role,” Information Systems Research, 16, pp. 372-399

46. Saari, D. G. (2001) “Decisions and elections: explaining the unexpected,” (1st ed.). Cambridge: Cambridge University Press

47. Siegler, R., and Talel, E. (2005) “Cooperatives and condominiums: Cumulative voting revisited,” New York Law Journal, 233(85), 231-233

48. Silver, S. D. (2014) “Designing technology for managing the information exchange of decision making teams,” Decision Support Systems, 61(1), pp. 136-146

49. Simon, H. A. (1972) “Theories of bounded rationality,” In McGuire C. B. \& Radner, R. eds., Decision and Organization, (pp. 161-176) Amsterdam: North-Holland Publishing Company. 
50. Simon, H. A. (1997) “Models of bounded rationality,” Cambridge, MA: MIT Press

51. Sobel, J. (2001) “Manipulation of Preferences and Relative Utilitarianism,” Games and Economic Behavior, 37(1), pp. 196-215

52. Steinel, W., and De Dreu, C. K. W. (2004) "Social motives and strategic misrepresentation in social decision-making,” Journal of Personality and Social Psychology, 86(3), pp. 419-434

53. Steinel, W., Utz, S., and Koning, L. (2010) "The good, the bad and the ugly thing to do when sharing information: Revealing, concealing and lying depend on social motivation, distribution and importance of information,” Organizational Behavior and Human Decision Processes, 113(2), pp. 85-96

54. Taylor, A. D. (2002) “The manipulability of voting systems,” The American Mathematical Monthly, 109(4), pp. 321-337

55. Taylor, A. D. (2005) “Social Choice and the Mathematics of Manipulation,” Cambridge, United Kingdom: Cambridge University Press

56. Twyman, N. W., Lowry, P. B., Burgoon, J. K., and Nunamaker Jr, J. F. (2014) “Autonomous Scientifically Controlled Screening Systems for Detecting Information Purposely Concealed by Individuals,” Journal of Management Information Systems, 31(3), 106-137

57. Vishwanath, A., Herath, T., Chen, R., Wang, J., and Rao, H. R. (2011) “Why do people get phished? Testing individual differences in phishing vulnerability within an integrated, information processing model,” Decision Support Systems, 51(3), pp. 576-586

58. Volz, K. G., Vogeley, K., Tittgemeyer, M., Von Cramon, D. Y., and Sutter, M. (2015) “The neural basis of deception in strategic interactions,” Frontiers in behavioral neuroscience, 9(27), pp. 9-27

59. Xia, L., and Conitzer, V. (2010) “Compilation complexity of common voting Rules,” In Proceedings of the 24th National Conference on Artificial Intelligence (AAAI-10), (pp. 
915-920). Atlanta, GA, USA, 2010: Association for Advancement of Artificial Intelligence

60. Xu, H., Kilgour, D. M., and Hipel, K. W. (2010) "Matrix representation and extension of coalition analysis in group decision support,” Computers and Mathematics with Applications, 60(5), pp. 1164-1176

61. Xiao, B., and Benbasat, I. (2011) "Product-related deception in e-commerce: a theoretical perspective,” MIS Quarterly, 35(1), pp. 169-196

62. Yang S., Li T., and van Heck, E. (2015) “Information transparency in prediction markets,” Decision Support Systems, 78, pp. 67-79

63. Zhou, L., Burgoon, J. K., Twitchell, D. P., Qin, T., and Nunamaker Jr, J. F. (2004) “A comparison of classification methods for predicting deception in computer-mediated communication,” Journal of Management Information Systems, 20(4), pp. 139-166

64. Zhu, H., Wang, P., and Bart, C. (2014) “Board Processes, Board Strategic Involvement, and Organizational Performance in For-profit and Non-profit Organizations,” Journal of Business Ethics, pp. 1-18

\section{Appendix A - Experiment Scenarios}

1. The Scenarios with No Access to Other People’s Preferences

Scenario 1.1: There are seven members in your vacation club. The club is to hold a vote on where to spend a summer vacation: the Azores, the Bahamas, or the Canaries. Personally, you prefer the Canaries to the Azores, but would not like the Bahamas. Please assign your single vote to a destination of your choice. A destination that receives the most votes wins.

The Azores: _. The Canaries: _. The Bahamas: _.

Scenario 1.2: You are a member of a sports club board. The board is composed of seven members, and you are to vote on whether to set up a section for basketball, football, or handball. 
Personally, you prefer football to basketball, but do not like handball. You are an insider. Please assign your single vote to a sports activity of your choice. A sports activity to receive the most votes wins.

$$
\text { Handball: _. Football: _. Basketball: _. }
$$

Scenario 1.3: Seven corporate board members are to travel to a ski resort. You are to vote on whether to travel to Aspen, Chamonix, or Cortina. Personally, you prefer Chamonix to Cortina, but do not like Aspen. Please assign your single vote to a ski resort of your choice. A ski resort to receive the most votes wins.

Cortina: _. Aspen: _. Chamonix: _.

Scenario 1.4: You are a member of a small business association. There are altogether seven members. These members are about to vote what business magazine to subscribe to: Forbes, BusinessWeek, or Fortune. Everyone will rank the magazines, and submit their rankings to the vote. You prefer Forbes to Fortune, but do not like BusinessWeek. Please rank the three magazines. Please do so by choosing 1 , 2, or 3 next to each of them. A magazine to receive the most first ranks wins.

BusinessWeek: _. Forbes: _. Fortune: _.

Scenario 1.5: You are a member of a committee on donations. The committee is composed of seven members, and is to vote on whether to make a donation to a political campaign, institution of fine arts, or charitable event. Everyone will rank the donations, and submit their rankings to the vote. You prefer the institution of fine arts to the charitable event. You do not want to contribute to the political campaign. Please rank the three donations. Please do so by choosing 1, 2, or 3 next to each of them. A donation to receive the most first ranks wins.

The Charitable Event:

The Institution of 
Scenario 1.6: You are a shareholder of a candy distributor. There are altogether seven shareholders, and all are to vote on a new supplier: Nestle SA, Hershey Foods Corporation, or Mars Inc. Everyone will rank the suppliers, and submit their rankings to the vote. You prefer Mars Inc. to Nestle SA. You do not like Hershey Foods Corporation. Please rank the three suppliers. Please do so by choosing 1, 2, or 3 next to each of them. A supplier to receive the most first ranks wins.

Mars Inc.: _ . Hershey Foods Corporation: _. Nestle SA: _.

Scenario 1.7: You are a member of an investment committee. The committee is composed of seven members, and is to vote on whether to invest in rice, corn, or soybeans. Each committee member will get three votes that are to be distributed across these three investments. Since you prefer soybeans to corn, and you do not like rice, you would give 2 votes to soybeans, 1 vote to corn, and 0 votes to rice. Please distribute your three votes across these three investments. The total sum of your votes has to equal three. An investment to receive the most votes wins.

Rice:__. Soybeans: _. Corn: _.

Scenario 1.8: Seven team members are to vote on a specific team building activity: paintball, bungee jumping, or rafting. Each team member will distribute three votes across these three activities. Since you prefer rafting to paintball, and you do not like bungee jumping, you would give 2 votes to rafting, 1 vote to paintball, and 0 votes to bungee jumping. Please distribute your three votes across these three activities. The total sum of your votes has to equal three. An activity to receive the most votes wins.

Rafting: _. Bungee Jumping: _. Paintball: _ 
Scenario 1.9: You and other six colleagues are to spend an evening out. You are to vote on whether to enjoy a symphony, theater play, or musical. Each manager will get three votes to distribute across these three outings. Since you prefer the theater to the musical, and you do not like the symphony, you would give 2 votes to the theater, 1 vote to the musical, and 0 votes to the symphony. Please distribute your three votes across these three options. The total sum of your votes has to equal three. An option to receive the most votes wins.

The Musical: _ . The Symphony: _ . The Theater Play: _.

\section{The Scenarios With Access to Other People’s Preferences}

Scenario 2.1: There are seven members in your vacation club. The club is to hold a vote on where to spend a summer vacation: the Azores, the Bahamas, or the Canaries. Personally, you prefer the Canaries to the Azores, but would not like the Bahamas. All these other six members would give 3 votes to the Bahamas and 3 votes to the Azores. Please assign your vote to a single destination of your choice. A destination that receives the most votes wins.

The Azores: _. The Canaries: _. The Bahamas: _.

Scenario 2.2: You are a member of a sports club board. The board is composed of seven members, and you are to vote on whether to set up a section for basketball, football, or handball. Personally, you prefer football to basketball, but do not like handball. Among these other six members, three members prefer basketball, and the other three members prefer handball. Please assign your single vote to a sports activity. A sports activity to receive the most votes wins.

Handball: _. Football: _. Basketball: __.

Scenario 2.3: Seven corporate board members are to travel to a ski resort. You are to vote on whether to travel to Aspen, Chamonix, or Cortina. Personally, you prefer Chamonix to Cortina, but do not like Aspen. Among these other six board members, three members are in 
favor of Aspen, and the remaining three members are in favor of Cortina. Please assign your single vote to a ski resort. A ski resort to receive the most votes wins.

Cortina: _. Aspen:__. Chamonix: _.

Scenario 2.4: You are a member of a small business association. There are altogether seven members. These members are about to vote what business magazine to subscribe to: Forbes, BusinessWeek, or Fortune. Everyone will rank the magazines, and submit their rankings to the vote. You prefer Forbes to Fortune, but do not like BusinessWeek. These other six members would give 3 first ranks and 3 third ranks to BusinessWeek, 1 second rank, 3 first ranks, and 2 third ranks to Fortune, and 1 third rank and 5 second ranks to Forbes. Please rank the three magazines. Please do so by choosing 1 , 2, or 3 next to each of them. A magazine to receive the most first ranks wins.

BusinessWeek: _. Forbes: _. Fortune: _.

Scenario 2.5: You are a member of a committee on donations. The committee is composed of seven members, and is to vote on whether to make a donation to a political campaign, institution of fine arts, or charitable event. Everyone will rank the donations, and submit their rankings to the vote. You prefer the institution of fine arts to the charitable event. You do not want to contribute to the political campaign. These other six members would give 1 third rank, 2 second ranks, and 3 first ranks to the political campaign, 4 third ranks and 2 second ranks to the fine arts, and 1 third rank, 3 first ranks, and 2 second ranks to the charitable event. Please rank the three donations. Please do so by choosing 1 , 2, or 3 next to each of them. A donation to receive the most first ranks wins.

The Charitable Event: 
Scenario 2.6: You are a shareholder of a candy distributor. There are altogether seven shareholders, and all are to vote on a new supplier: Nestle SA, Hershey Foods Corporation, or Mars Inc. Everyone will rank the suppliers, and submit their rankings to the vote. You prefer Mars Inc. to Nestle SA. You do not like Hershey Foods Corporation. These other six shareholders would give 1 second rank, 2 third ranks, and 3 first ranks to Hershey Foods Corporation, 1 third rank and 5 second ranks to Mars, and 3 first ranks and 3 third ranks to Nestle SA. Please rank the three suppliers. Please do so by choosing 1, 2, or 3 next to each of them. A supplier to receive the most first ranks wins.

Mars Inc. : H. H ershey Foods C orporation: N est

Scenario 2.7: You are a member of an investment committee. The committee is composed of seven members, and is to vote on whether to invest in rice, corn, or soybeans. Each committee member has three votes that are to be distributed across these three investments. Since you prefer soybeans to corn, and you do not like rice, you would give 2 votes to soybeans, 1 vote to corn, and 0 votes to rice. These six members would give 7 votes to corn, 6 votes to rice, and 5 votes to soybeans. Please distribute your 3 votes across these three investments. The total sum of your votes has to equal 3. An investment to receive the most votes wins.

Rice:__. Soybeans: _. Corn:__.

Scenario 2.8: Seven team members are to vote on a specific team building activity: paintball, bungee jumping, or rafting. Each team member will distribute three votes across these three activities. Since you prefer rafting to paintball, and you do not like bungee jumping, you would give 2 votes to rafting, 1 vote to paintball, and 0 votes to bungee jumping. These six members would give 8 votes to bungee jumping, 6 votes to paintball, and 4 votes to rafting. Please distribute your 3 votes across these three activities. The total sum of your votes has to equal 3. An activity to receive the most votes wins. 
Rafting: _. Bungee Jumping: __. Paintball: _.

Scenario 2.9: You and other six colleagues are to spend an evening out. You are to vote on whether to enjoy a symphony, theater play, or musical. Each manager will get three votes to distribute across these three outings. Since you prefer the theater to the musical, and you do not like the symphony, you would give 2 votes to the theater, 1 vote to the musical, and 0 votes to the symphony. These six managers would give 7 votes to the theater play, 2 votes to the symphony, and 9 votes to the musical. Please distribute your 3 votes across these three options. The total sum of your votes has to equal 3. An option to receive the most votes wins.

The Musical: __. The Symphony: _ . The Theater Play: _.

\section{Appendix B - Social Value Orientation Questionnaire}

We employed a questionnaire (Murphy et al. 2011) in order to compute this orientation. Our participants were asked to choose a position on a nine point scale between 1) being altruistic and competitive, 2) individualistic and equitable, 3) individualistic and altruistic, 4) competitive and individualistic, 5) altruistic and equitable, and 6) equitable and competitive. An index is then

computed as: $s v o=\arctan \left(\frac{a_{o}-50}{a_{s}-50}\right)$ where $a_{s}$ is the mean allocation for the subject, and $a_{o}$ is their mean allocation for the imaginary other (Murphy et al., 2011). 


\begin{tabular}{|c|c|c|c|c|c|c|c|c|c|c|}
\hline Table 1. & Column 1 & Column 2 & Column 3 & Column 4 & Column 5 & Column 6 & Column 7 & Column 8 & Column 9 & \multirow{3}{*}{ Competitive } \\
\hline \multirow{3}{*}{ Altruistic } & 50 & 54 & 59 & 63 & 68 & 72 & 76 & 81 & 85 & \\
\hline & 100 & 89 & 79 & 68 & 58 & 47 & 36 & 26 & 15 & \\
\hline & 150 & 143 & 138 & 131 & 126 & 119 & 112 & 107 & 100 & \\
\hline & & & & & & & & & & \\
\hline Table 2. & Column 1 & Column 2 & Column 3 & Column 4 & Column 5 & Column 6 & Column 7 & Column 8 & Column 9 & \\
\hline \multirow{3}{*}{ Individualistic } & 100 & 98 & 96 & 94 & 93 & 91 & 89 & 87 & 85 & \multirow{2}{*}{ Equitable } \\
\hline & 50 & 54 & 59 & 63 & 68 & 72 & 76 & 81 & 85 & \\
\hline & 150 & 152 & 155 & 157 & 161 & 163 & 165 & 168 & 170 & \\
\hline & & & & & & & & & & \\
\hline Table 3. & Column 1 & Column 2 & Column 3 & Column 4 & Column 5 & Column 6 & Column 7 & Column 8 & Column 9 & \\
\hline \multirow{3}{*}{ Individualistic } & 100 & 94 & 87 & 81 & 75 & 69 & 63 & 56 & 50 & \multirow{2}{*}{ Altruistic } \\
\hline & 50 & 56 & 63 & 69 & 75 & 81 & 87 & 94 & 100 & \\
\hline & 150 & 150 & 150 & 150 & 150 & 150 & 150 & 150 & 150 & \\
\hline Table 4. & Column 1 & Column 2 & Column 3 & Column 4 & Column 5 & Column 6 & Column 7 & Column 8 & Column 9 & \\
\hline \multirow{3}{*}{ Competitive } & 85 & 87 & 89 & 91 & 93 & 94 & 96 & 98 & 100 & \multirow{2}{*}{ Individualistic } \\
\hline & 15 & 19 & 24 & 28 & 33 & 37 & 41 & 46 & 50 & \\
\hline & 100 & 106 & 113 & 119 & 126 & 131 & 137 & 144 & 150 & \\
\hline Table 5. & Column 1 & Column 2 & Column 3 & Column 4 & Column 5 & Column 6 & Column 7 & Column 8 & Column 9 & \\
\hline \multirow{3}{*}{ Altruistic } & 50 & 54 & 59 & 63 & 68 & 72 & 76 & 81 & 85 & \multirow{2}{*}{ Equitable } \\
\hline & 100 & 98 & 96 & 94 & 93 & 91 & 89 & 87 & 85 & \\
\hline & 150 & 152 & 155 & 157 & 161 & 163 & 165 & 168 & 170 & \\
\hline Table 6. & Column 1 & Column 2 & Column 3 & Column 4 & Column 5 & Column 6 & Column 7 & Column 8 & Column 9 & \\
\hline \multirow{3}{*}{ Equitable } & 85 & 85 & 85 & 85 & 85 & 85 & 85 & 85 & 85 & \multirow{2}{*}{ Competitive } \\
\hline & 85 & 76 & 68 & 59 & 50 & 41 & 33 & 24 & 15 & \\
\hline & 170 & 161 & 153 & 144 & 135 & 126 & 118 & 109 & 100 & \\
\hline
\end{tabular}

